it possible to formulate a theory of the chemistry of the process involved. Secondly, by the application of modern biochemical technique, the actual synthesis of thyroxine from diiodotyrosine has been demonstrated in surviving thyroid tissue in vitro. The latter type of experiment incidentally offers an opportunity for the analytical study of the action of substances such as thiourea, which inhibit thyroid activity supposedly by interfering with the biosynthesis of the hormone.

Accepting the mechanisism of biosynthesis of thyroxine as being satisfactorily established, we are left with two outstanding problems. Is thyroxine itself the actual circulating thyroid hormone, and, if so, by what mechanism does it exercise its effect in the periphery? To the second of these questions no answer can yet be given. Evidence regarding the first is conflicting, and in the attempt to obtain a definitive answer an approach has been made along a new line which raises matters of some general interest. The method is based on the theory, deduced from the known facts of immunological chemistry, that an antigen of which the determinant group is a physiologically active substance should give rise to an antiserum capable of inhibiting the characteristic activity of this substance. Application of this idea to the problem of thyroxine involved the develop. ment of a new technique for building up artificial antigenic complexes. Such a complex containing thyroxine as the determinant group has proved to be able to give rise to an antiserum which can inhibit the physiological action both of a protein containing thyroxine, such as thyroglobulin, and of thyroxine itself. The latter observation, together with extension of the experimental method to an entirely different compound, favours the hypothesis that thyroxine itself is in fact the actual circulating thyroid hormone.

\section{INCIDENCE OF RICKETS IN GREAT BRITAIN}

D URING the six weeks from mid-January to the end of February 1943 the British Pædiatric Association carried out a combined clinical and radiological investigation into the frequency of rickets in twenty-three areas of Britain and Ireland*. Out of a total of 5,283 children aged 3-18 months, 106 only were reported to show radiological evidence of rickets. Dr. Percy Stocks, who analysed the returns, concluded that the incidence of rickets, diagnosed radiologically, was 2.5 per cent before six months, 4 per cent during the first year and negligible after the first year. The incidence was highest in Ireland and lowest in South England. In Watford and St. Albans no case was detected even by clinical methods. There is no evidence of any increase in the incidence or severity of rickets during the War. In some of the cities of north England, older children with deformities due to severe rickets may still be seen, whereas the cases found in this investigation were slight and free from any gross deformity. It may be inferred that severe rickets was more common a few years ago.

Two points stand out. First, the number of cases diagnosed by clinical methods was nearly ten times the number diagnosed radiologically. Even the three

* Reports on Pub. Health and Medical Subjects, No. 92. "The Incidence of Rickets in War-time". Pp. 36. (London : H.M. Stationery Office.) $9 d$. net. radiologists who examined the films differed in their interpretations. Obviously, we do not yet know what constitutes evidence of slight rickets. But this disagreement is itself evidence of the mildness of the disease, for there is no mistaking severe rickets.

Secondly, $85 \cdot 5$ per cent of the babies that were considered to have rickets on $\mathrm{X}$-ray evidence had had some form of treatment with vitamin $D$. On this point the report is disappointing. Examiners were supposed to find out what preparation was used, when dosage began, and the daily dose given; but analysis in terms of the duration of vitamin $D$ prophylaxis and the dosage was not attempted, and the nature of the preparations used is not mentioned in the report. It is little use saying that "scientific evidence has clearly shown that adequate vitamin $\mathrm{D}$ administered in an adequate dosage and in a suitable form will prevent rickets", and that "a common cause of rickets is the popular cod liver oil-and-malt", without inquiry into the reasons why 77 out of 4,317 babies who were given vitamin D got rickets. The fashion of handing over the results of an investigation for mechanical analysis by a statistician who may not appreciate the importance of the problems that may be involved has its disadvantages.

\section{MODERN ASPECTS OF INORGANIC CHEMISTRY}

$\mathrm{T}$ HE presidential address by Prof. R. C. Ray to the Chemistry Section of the Indian Science Congress at Delhi dealt with some aspects of modern inorganic chemistry. After mentioning that research in in anic chemistry had declined towards the close of the nineteenth century, mainly because of the very rapid development of organic chemistry and the rise of physical chemistry, he pointed out that there are very many new aspects of the subject now being developed.

Prof. Ray went on to describe some interesting developments. Compounds of the inert gases with water, boron fluoride and phenol have been obtained, and compounds with metals such as mercury, and iodine, sulphur and phosphorus are described. A subject which has been fully studied, particularly by Stock, Wiberg, Bauer and others, is the chemistry of the hydrides of boron and related eompounds, which are also of great interest in relation to the electronic theory of valency. In this field, Indian workers have made important contributions, particularly Prof. Ray and his pupils, who have also worked on the chemistry of co-ordination compounds, glass and hydrides of metals such as nickel.

Nickel forms two hydrides, $\mathrm{NiH}$ and $\mathrm{NiH}_{2}$, and cobalt forms analogous compounds, the heats of formation being comparable with those of the saltlike hydrides of the alkali and alkaline earth metals. The heats of formation of hydrides of some rareearth metals, zirconium, tantalum and titanium, generally regarded as interstitial compounds, are also of the same order, this suggesting that there can be little difference in the nature of the chemical bond in such substances as zirconium hydride and barium hydride, with nearly equal heats of formation.

Prof. Ray considers that there has probably never been a time when the prospects of inorganic chemistry were so promising as they are to-day, when new methods in physics, physical chemistry and organic chemistry are available. 